\title{
Study on Driving Forces in Quantity Changes of Cultivated Land in Yubei District, Chongqing, China
}

\author{
Qiang Zheng ${ }^{1} \&$ Ruiping Ran $^{1}$ \\ ${ }^{1}$ College of Economics and Management, Sichuan Agricultural University, Chengdu, China \\ Correspondence: Qiang Zheng, College of Economics and Management, Sichuan Agricultural University, \\ Chengdu 611130, Sichuan, China. E-mail: zhengqiang27@yahoo.com.cn
}

Received: March 14, 2012

Accepted: April 3, $2012 \quad$ Published: May 1, 2012

doi:10.5539/ass.v8n6p209

URL: http://dx.doi.org/10.5539/ass.v8n6p209

\begin{abstract}
In the past few years, with continuous increase in population and rapid development of economy, the total quantity of cultivated land in Yubei District in Chongqing has reduced year by year and the binary relation between changes in cultivated land and economic growth becomes more prominent. In this article, the authors use the statistic data between the year 1997 and the year 2006 to analyze and discuss changes in cultivated land area in the past decade in Yubei District and further discuss the driving factors that affect changes in utilization of cultivated land by using the principal component analysis method on that basis and set up a multiple regression model. The research result shows that, the total tendency of the quantity of cultivated land in Yubei District exhibits a declining trend year by year and changes in cultivated land protection policy, permanent asset investment and agricultural population conversion level are the major macro driving factors that affect changes in the quantity of cultivated land in Yubei District. Therefore, it will be critical in determining changes in quantity of cultivated land in Yubei District in the future to persistently carry out and implement the national cultivated land protection policy, enlarge investment in land consolidation and coordinate contradictions between economic development and cultivated land protection.
\end{abstract}

Keywords: quantity of cultivated land, driving forces, Yubei district

\section{Problems Proposed}

Cultivated land is a sort of nonrenewable natural resource with limited quantity. Its changes in quantity, to a certain extent, reflect the development condition of the social economy and it has an important influence upon food security and it is also one of the central factors in studying land security and even ecological security (Jin Fengjun, Zhang Xiaoping, et al., 2004). With accelerated progress of urbanization, the total quantity of cultivated land in Yubei District and per capita cultivated land acreage have been continuously reduced, which has already affected sustainable development of social economy in Yubei District and has aroused wide attention from the government and all the society. Thus, it has become a problem that needs to be urgently resolved how to take reasonable measures to mitigate contradictions between development of social economy and shrinking of cultivated land. This article is going to explore the internal rules of development of cultivated land and offer evidence for coordinating contradictions between economic development and shrinking cultivated land in Yubei District by means of setting up an econometric model of driving forces of changes in cultivated land area in Yubei District.

\section{Overview of the Research Area}

Yubei District in Chongqing is located in the northern part of Chongqing City and the area under its jurisdiction borders on Linshui County and Huaying City in Sichuan Province. Its terrain slowly inclines from the northwest to the southeast and crosses East Longitude 106 $27^{\prime} 30^{\prime \prime}-106^{\circ} 57^{\prime} 58^{\prime \prime}$ and Northern Latitude $29^{\circ} 34^{\prime} 45^{\prime \prime}-30^{\circ} 07^{\prime} 22^{\prime \prime}$, with a territory area of 1452 square kilometers, including an area of 41.3 thousand hectares of cultivated land and with 14 streets and 12 towns under its jurisdiction. In 2010, the total population of Yubei District was 1.3454 million and its GDP was as much as 55 billion RMB Yuan. In the past few years, with further implementation of the develop-the-west strategy and accelerated propelling of coordinated development of urban and rural areas in Chongqing, the progress of urbanization in Yubei District has expedited, demand on non-agricultural construction land is on a rapid increase and the quantity of cultivated land sharply declines, so Yubei District is faced up with an austere challenge in protection of cultivated land.

\section{An Analysis of Process of Changes in Quantity of Cultivated Land in Yubei District}

According to the land use change survey data in Yubei District, the cultivated land area in Yubei District has 
generally presented a declining curve (as shown in Table 1) ever since Chongqing was directly under the jurisdiction of the Central Government. The cultivated land area declined from $60483.33 \mathrm{hm}^{2}$ in 1997 to $45832.55 \mathrm{hm}^{2}$ in 2006 , with a net decline of $14650.78 \mathrm{hm}^{2}$ and an annual cultivated land lapse rate of $2.69 \%$. Generally speaking, the process of changes in quantity of cultivated land in Yubei District has undergone the three stages of slow decline --- sharp decline --- relatively fast decline (as shown in Figure 1). Cultivated land between the year 1997 and 2000 was at a relatively stable period, during which the quantity of cultivated land slows declined, which was mainly because that the nation at that time carried out a strict cultivated land protection policy and Yubei District was at the initial stage of rapid urbanization. The quantity of cultivated land in Yubei District between the year 2001 and 2004 sharply declined, during which New North Zone, Free Trade Port Area and Chongqing Hitech Park Zone were settled down in Yubei District owing to the obvious location advantages of Yubei District, which rapidly propelled the progress of urbanization. Rapid increase of non-agricultural construction land, rapid development of social economy and ecological conceding of land are the major factors that caused sharp decline in quantity of cultivated land in Yubei District. Ever since the year 2005, with further development of Yubei District and rapid propelling of coordinated development of urban and rural areas in Chongqing, the quantity of cultivated land in Yubei District continued to decline, but the declining scope was relatively small compared with the former period. Considering the direction of decline in cultivated land, on one hand, use of cultivated land was changed, such as, agricultural structural adjustment and non-agricultural land construction, etc. On the other hand, the productive capacity of cultivated land was weakened, such as, disaster and pollution, etc. Considering the sources of increase in cultivated land, the approaches to increase in cultivated land in Yubei District were land consolidation, unused land development, reclamation of land and other approaches. Since the backup cultivated land resources in Yubei District were difficult to develop, the quantity of increase in cultivated land between the year 1997 and the year 2006 was $673.71 \mathrm{hm}^{2}$, far less than the quantity of decline in cultivated land, which means it is difficult to get a basic balance of the quantity of cultivated land.

Table 1. Changes of cultivated land in Yubei District in 1997-2006

Unit: $\mathrm{hm}^{2}$

\begin{tabular}{lc}
\hline Year & Cultivated land area of national land department \\
\hline 1997 & 60483.33 \\
1998 & 59712.16 \\
1999 & 59020.83 \\
2000 & 58615.99 \\
2001 & 58540.37 \\
2002 & 56041.47 \\
2003 & 51992.47 \\
2004 & 48444.39 \\
2005 & 46356.96 \\
2006 & 45832.55 \\
\hline
\end{tabular}

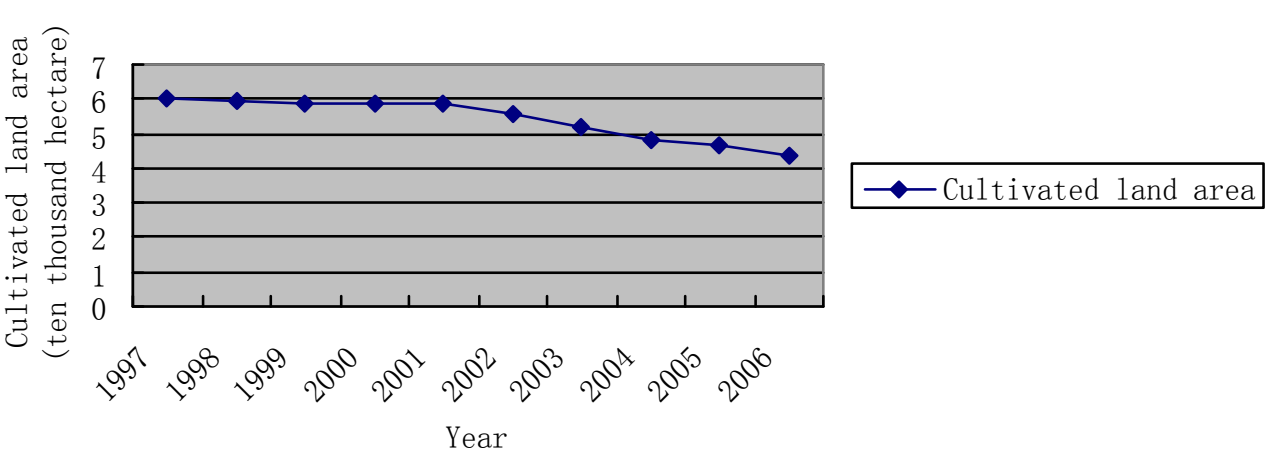

Figure 1. Changes in cultivated land area in Yubei District 


\section{An Analysis of Driving Forces in Changes of the Quantity of Cultivated Land in Yubei District}

\subsection{An Analysis of Driving Factors in Changes of the Quantity of Cultivated Land}

Driving factors for changes in cultivated land mainly include the two categories of natural factors and social and economic factors. Natural factors have no obvious influence upon changes in land utilization. However, social and economic factors have obvious changes, so we here mainly make an analysis of influences of social and economic factors on quantity of cultivated land. From the above analysis, it can be found that, decline in cultivated land in Yubei District is almost synchronous with the economic development level. Thus, it can be seen that economic development is a primary influential factor that affects changes in cultivated land in Yubei District and the direct result caused by the economic factor is expansion of non-agricultural construction, which is a direct driving factor that affects changes in cultivated land. In addition, such social and economic factors as population growth, population urbanization, scientific and technical progress, policy orientation, intensive land use and planting system are also driving factors that affect changes in the quantity of cultivated land.

\subsection{Econometric Analysis of Changes in Quantity of Cultivated Land}

On the basis of qualitative analysis, considering relevant data about Yubei District, this article uses SPSS software, employs the principal component analysis and regression analysis method to make an analysis of social and economic data and data about quantity of cultivated land between the year 1997 to 2006, employs the principal component analysis method to analyze relevant driving factors that affect changes in the quantity of cultivated land in Yubei District and sets up a multiple regression model. This offers scientific evidence for rational utilization and protection of cultivated land and sustainable development of agriculture.

\subsubsection{Selection of Factors}

According to the train of thought and requirement of the principal component analysis and by considering the current data of Yubei District, we select the sequence data between the year 1997 and 2006 as the basic data and select ten influential factors, namely, $\mathrm{X}_{1}$ as the total population (ten thousand), $\mathrm{X}_{2}$ as the per unit yield of food (Ton/hectare), $\mathrm{X}_{3}$ as the agricultural population conversion level (\%), $\mathrm{X}_{4}$ as GDP (0.1 billion Yuan), $\mathrm{X}_{5}$ as the permanent asset investment ( 0.1 billion Yuan), $\mathrm{X}_{6}$ as the non-agricultural proportion (\%), $\mathrm{X}_{7}$ as the variable of cultivated land protection policy (1-10), $\mathrm{X}_{8}$ as the industrial structure adjustment variable (\%), $\mathrm{X}_{9}$ as the population density (person/square kilometer) and $\mathrm{X}_{10}$ as the construction land area (hectare). $\mathrm{Y}$ is the quantity of cultivated land (ten thousand/hectare).

The variable of cultivated land protection policy reflects influences of cultivated land protection policies with different strengths on changes in cultivated land. In order to quantify the variable of cultivated land protection policy, here the authors employ Delphi Method and define the cultivated land protection policy between 1980 and 1985 as "1" (namely, protecting and implementing the cultivated land protection policy prior to "Land Management Law") during which period the cultivated land protection was at a weak protection condition. The cultivated land protection policy between 1986 and 1994 was defined as "3", during which China began to put into effect "Land Management Law", and the cultivated land protection policy was at a relatively stronger condition. The cultivated land protection policy between 1995 and 1996 was defined as " 5 ", during which period China began to carry out the basic farmland protection system, and the cultivated land protection policy was at an intensified cultivated land protection condition. The cultivated land protection policy between 1997 and 1998 was defined as " 8 ", which was mainly because China began to carry out the land use regulation system in 1997. The cultivated land protection policy between 1999 and 2006 was defined as "10", which was mainly because the new "Land Management Law" was implemented in 1999. Industrial structure adjustment variable is expressed by the proportion of the planting area of food crops to the total sowing area of agricultural crops, which is used to test the related relation between agricultural industrial structure adjustment and changes in the quantity of cultivated land (Tan Rong \& Wu Limei, 2004)

\subsubsection{Principal Component Analysis of Factors}

Study in this article mainly uses the principal component method, which follows the principles of scientificity, systematicness, regionality and maneuverability. Considering the current natural and social and economic data about Yubei District, the authors select data between 1997 and 2006 of the above variables as the analysis sample (shown in Table 2), apply the statistic software of data processing system SPSS to make an analysis and calculation of the sample and get related coefficient matrix, eigenvalue and contribution rate of the principal component. 
Table 2. Data of principal component analysis

\begin{tabular}{llllllllllll}
\hline Year & $\mathrm{Y}$ & $\mathrm{X}_{1}$ & $\mathrm{X}_{2}$ & $\mathrm{X}_{3}$ & $\mathrm{X}_{4}$ & $\mathrm{X}_{5}$ & $\mathrm{X}_{6}$ & $\mathrm{X}_{7}$ & $\mathrm{X}_{8}$ & $\mathrm{X}_{9}$ & $\mathrm{X}_{10}$ \\
\hline 1997 & 60483.33 & 78.62 & 3835 & 9.94 & 31.91 & 7.98 & 86.16 & 8 & 45.11 & 768.2 & 18197.98 \\
1998 & 59712.16 & 79.13 & 3469 & 11.21 & 38.15 & 13.94 & 89.15 & 8 & 44.3 & 769.6 & 18276.06 \\
1999 & 59020.83 & 79.53 & 3730 & 11.96 & 40.56 & 15.16 & 90.02 & 10 & 43.91 & 775.4 & 18338.72 \\
2000 & 58615.99 & 80.26 & 2490 & 12.28 & 45.98 & 16.92 & 92.19 & 10 & 43.73 & 776.1 & 18726.10 \\
2001 & 58540.37 & 80.78 & 2940 & 12.57 & 48.64 & 18.96 & 92.72 & 10 & 42.73 & 781.5 & 20369.40 \\
2002 & 56041.47 & 82.09 & 2795 & 12.75 & 56.55 & 19.85 & 94.87 & 10 & 42.63 & 786.6 & 22590.45 \\
2003 & 51992.47 & 84.84 & 3086 & 13.23 & 67.75 & 21.74 & 96.61 & 10 & 41.91 & 787.1 & 23030.53 \\
2004 & 48444.39 & 86.58 & 3162 & 13.52 & 105.13 & 38.43 & 98.36 & 10 & 40.69 & 788.2 & 24418.95 \\
2005 & 46356.96 & 88.54 & 3024 & 13.84 & 140.41 & 41.42 & 98.94 & 10 & 38.57 & 789.3 & 24437.91 \\
2006 & 45832.55 & 90.18 & 3056 & 14.32 & 183.11 & 65.22 & 98.95 & 10 & 36.97 & 789.4 & 24851.85 \\
\hline
\end{tabular}

Considering the operation results, different correlation exists between the eleven factors that affect changes in the quantity of cultivated land. Great correlation exists between $X_{1}$ and $X_{3}$ and between $X_{6}$ and $X_{10}$, with a related coefficient of respectively 0.965 and 0.983 , which indicates the necessity of the principal component analysis. The cumulative contribution rate of the first principal component, the second principal component and the third principal component has respectively achieved $94.351 \%$, which completely corresponds with the requirement of the analysis. Thus, we further work out the principal component loading matrix, which is a related coefficient of the principal component and variables. The larger the loading coefficient, the greater the influence of the factor on the variables. In the column of the first principal component, agricultural population conversion level, construction land area, GDP and non-agricultural proportion all have strong positive correlation with the loading coefficient. In the column of the second principal component, population density has strong positive correlation with the loading coefficient. In the third column of the third principal component, per unit yield of food and cultivated land protection policy variable both have certain correlation with the loading coefficient.

Hence, the driving forces of changes in the quantity of cultivated land in Yubei District can be summarized as the three major categories of economic development and policy trend factor, population density influence factor and agricultural scientific and technical factor through the principal component analysis.

4.2.3 Establishment of the Model

Through the above principal component analysis, we have discussed the single factor correlation between changes in cultivated land and driving factors and ascertained relative importance of driving indexes. On that basis, through a gradual regression analysis, we set up a model of driving forces between changes in cultivated land and humanistic factors, regard the cultivated land area as the dependent variable and the all variables in the correlation analysis as the independent variables, make a gradual regression analysis with the statistic software SPSS and get the results as in Table 3 and Table 4.

Table 3. Summary of the regression model about changes in cultivated land in Yubei District

\begin{tabular}{llcccc}
\hline Model & Related & \multicolumn{2}{c}{$\begin{array}{l}\text { Squared } \\
\text { value of } \\
\text { related } \\
\text { coefficient }\end{array}$} & $\begin{array}{c}\text { Squared value of } \\
\text { adjusted related } \\
\text { coefficient }\end{array}$ & $\begin{array}{c}\text { Standard error of } \\
\text { estimated } \\
\text { value }\end{array}$ \\
\hline $1 \quad$ & $\begin{array}{c}\text { Cultivated land } \\
\text { protection } \\
\text { policy }\end{array}$ & 0.714 & 0.518 & 0.454 & 197.018 \\
\hline $\begin{array}{c}\text { Permanent asset } \\
\text { investment } \\
\text { Agricultural } \\
\text { population } \\
\text { conversion level }\end{array}$ & 0.903 & 0.817 & 0.774 & 127.112 \\
\hline
\end{tabular}


Table 4. Regression coefficient about changes in cultivated land in Yubei District

\begin{tabular}{|c|c|c|c|c|c|c|}
\hline Model & & $\begin{array}{l}\text { Unst } \\
\text { coefficients }\end{array}$ & $\begin{array}{l}\text { dized } \\
\text { Error } \\
\text { coefficient } \\
\text { of variable } \\
\text { standard }\end{array}$ & $\begin{array}{l}\text { Standardized } \\
\text { coefficient }\end{array}$ & Test value & $\begin{array}{l}\text { Level of } \\
\text { significance }\end{array}$ \\
\hline \multirow[t]{2}{*}{1} & (Constant) & 46235.82 & 362.1644 & & 127.6652 & $5.64 \mathrm{E}-15$ \\
\hline & $\mathrm{X}_{7}$ & 118.6352 & 38.90948 & 0.712811 & 3.049001 & 0.013814 \\
\hline \multirow[t]{3}{*}{2} & (Constant) & 45972.11 & 177.7948 & & 258.5682 & $5.6 \mathrm{E}-16$ \\
\hline & $\mathrm{X}_{7}$ & 180.6704 & 21.44242 & 1.08556 & 8.425867 & $3 \mathrm{E}-04$ \\
\hline & $\mathrm{X}_{5}$ & -3.65502 & 0.645208 & -0.72986 & -5.66496 & 0.000472 \\
\hline \multirow[t]{4}{*}{3} & (Constant) & 44626.74 & 528.0716 & & 84.49186 & $8.57 \mathrm{E}-11$ \\
\hline & $\mathrm{X}_{7}$ & 98.39378 & 34.99642 & 0.591188 & 2.811513 & 0.026088 \\
\hline & $\mathrm{X}_{5}$ & -6.37528 & 1.138257 & -1.27458 & -5.60784 & 0.000808 \\
\hline & $X_{3}$ & 163.9559 & 61.82203 & 0.930269 & 2.651883 & 0.032853 \\
\hline
\end{tabular}

With the analysis result, we set up a multiple linear regression model about relationship between cultivated land area in Yubei District and the driving factors:

$$
\mathrm{Y}=44626.74+98.39378 \mathrm{X}_{7}-6.37528 \mathrm{X}_{5}+163.9559 \mathrm{X}_{3}
$$

Where, $\mathrm{Y}$ stands for the cultivated land area, $\mathrm{X}_{7}$ stands for cultivated land protection policy, $\mathrm{X}_{10}$ stands for permanent asset investment and $\mathrm{X}_{3}$ stands for agricultural population conversion level and, where, it is indicated that cultivated land protection policy, permanent asset investment and agricultural population conversion level are the leading driving factors that lead to changes in the quantity of cultivated land in Yubei District.

\section{Conclusions and Suggestions}

The quantity of cultivated land area in Yubei District has, for the first time, presented a slowly stable period ever since the trend of continuously decreasing progressively in 1997, which is a combined result of multiple factors of population growth and economic development, etc. The leading driving factor is cultivated land protection policy, permanent asset investment and agricultural population conversion level. Thus, the authors propose the following several suggestions.

(1) It is necessary to persistently carry out and implement the national cultivated land protection policy and, according to the actual situation, practically protect cultivated land and control the speed of decline in cultivated land. We have to optimize industrial structure adjustment, enhance the land utilization threshold, satisfy with priority excellent and highly effective industrial projects, facilitate industrial upgrading and realize maximization of social and economic benefits in Yubei District.

(2) It is necessary to carry out a rational overall plan of land utilization, strengthen land consolidation and investment, efficiently use land in inventory and promote connection of increase of urban construction land with decline of rural collective construction land. We have to regard science and technology and modern management idea as the support, tap internal potentials, economize land utilization, and further enhance the land utilization efficiency and output rate of land and realize "increasing income and reducing expenditure" of land.

(3) It is necessary to strictly control rural population growth, transfer economic development mode, develop resource conserving and environmentally friendly economy, deal with the relationships between population, environment, economic development and cultivated land protection in a correct way and promote sustainable development of social economy in Yubei District.

\section{References}

Cai, Yinying, \& Zhang, Anlu. (2004). Analysis on the Evolution Characteristics of Cultivated Land NonAgriculturalization in Wuhan City in Recent Years. China Population Resources and Environment, 14(6), 115-119.

Chongqing Statistical Bureau. Statistical Yearbook in Chongqing (1997-2007). Beijing: China statistical publishing house.

Jin, Fengjun, \& Zhang, Xiaoping. (2004). Land Use Problems and Intensive Utilization Patterns in the Coastal 
Regions of China. Resource Science, 26(5), 53-60.

Li, Jianqiang, Ren, Dating, \& Wu, Xiyu. (2002). The Change and Driving Forces of Cultivated Land Quantity in Sichuan Province. Journal of Sichuan Agricultural University, 17(2), 215-220.

Shao, Xiaomei, Yang, Qinye, \& Zhang, Hongye. (2001). A study on trend and driving forces of cultivated land use change in Shandong Province. Geographical Research, 20(3), 298-306.

Tan, Rong, \& Wu, Limei. (2004). An Analysis of Driving Force of Cultivated Land Change --Taking Sichuan Province as an Example. Scientific and Technological Management of Land and Resources, (6), 125-129.

Wang, Weiguo. (2002). Econometrics. Dalian: Dongbei University of Finance and Economics Press.

Xu, Xianli, Cai Yumei, \& Zhang, Keli. (2005). Study on Dynamic Change of Cultivated Land Resources and Causes of the Changes. China Population Resources and Environment, 15(3), 75-79.

$\mathrm{Xu}$, Yueqing, \& Li, Xiubin. (2001). Analysis of Dynamic Change and Driving Forces of Farmland in Hebei Province. Resource Science, 23(5), 28-32.

Zhai, Wenxia, \& Huang, Xianjin. (2003). Analysis on the Effect of Policies Operation of Cultivated Land Protection in China. China Land Science, (2), 8-13. 